\title{
Novel Production Method for Plant Polyphenol from Livestock Excrement Using Subcritical Water Reaction
}

\author{
Mayu Yamamoto, Yasuhiro Futamura, Kouki Fujioka, and Kenji Yamamoto \\ Department of Medical Ecology and Informatics, Research Institute, International Medical Center of Japan, Toyama 1-21-1, \\ Shinjuku-ku, Tokyo 162-8655, Japan \\ Correspondence should be addressed to Kenji Yamamoto, backen@ri.imcj.go.jp
}

Received 8 February 2008; Accepted 14 May 2008

Recommended by Ram B. Gupta

Plant polyphenol, including vanillin, is often used as the intermediate materials of the medicines and vanilla flavoring. In agriculture generally vanillin is produced from vanilla plant and in industry from lignin of disposed wood pulp. We have recently developed a method for the production of plant polyphenol with the excrement as a natural resource of lignin, of the herbivorous animals, by using the subcritical water. The method for using the subcritical water is superior to that of the supercritical water because in the latter complete decomposition occurs. We have successfully produced the vanillin, protocatechuic acid, vanillic acid, and syringic acid in products. Our method is simpler and more efficient not only because it requires the shorter treatment time but also because it releases less amount of carbon dioxide into the atmosphere.

Copyright ( $) 2008$ Mayu Yamamoto et al. This is an open access article distributed under the Creative Commons Attribution License, which permits unrestricted use, distribution, and reproduction in any medium, provided the original work is properly cited.

\section{Introduction}

Livestock excrement in Japan alone has been attained up to 40000 tons per year, which recently has been one of the national major excrement management problems. Almost all farms are located close to residential areas in Japan, which enhances the hazard of water and soil pollution by the bad smell and by the onset of the potential infectious diseases. Therefore, we have to develop the method of disposing the excrement efficiently and safely. In order to regulate the pollution, the Japanese government passed the law, "Law concerning the appropriate treatment and promotion of utilization of livestock manure" (universally applied on November 1st, 2004) [1]. The law requires the standardization of management method. It is required to build covered and walled-off structures for the disposal of solid excrement with the concrete floors or other nonpermeable materials. As for the disposal of liquid excrement and slurry, it is required to build tanks made of concrete or nonpermeable material. According to the law the livestock excrement should not be piled up in open air, which usually leads to a long time on making the composts.
There has been another method to develop the electric power station with supercritical water reactor to treat the livestock excrements in a company Miyazaki Biomass Recycle (Miyazaki, Japan), Shizuoka University (Shizuoka, Japan), and the Japan Aerospace Exploration Agency (JAXA) [24], the former with chicken excrement and the latter two with cattle excrement. In this case, however, the livestock excrement as a natural resource decomposes into carbon dioxide gas $\left(\mathrm{CO}_{2}\right)$ and water $\left(\mathrm{H}_{2} \mathrm{O}\right)$.

It is known that the livestock excrement contains a large quantity of indigestible dietary fibers of lignin. Lignin is a biopolymer in which hydroxyphenylpropane units such as trans-p-coumaryl alcohol, coniferyl alcohol, and sinapyl alcohol are connected with ether and carbon-carbon linkages in a helical structure [5-10]. Nakahara reported extraction of the plant polyphenol from wood pulp using supercritical water [11]. Adschiriand colleagues also reported extraction of the plant polyphenol by solvothermal reaction [12-15]. The plant polyphenol including vanillin is very useful for intermediate material of the medicines and food flavor. Vanillin is currently extracted from vanilla plant conventionally. Japan imported 260 tons and 340 tons of 
vanillin per year in 2004 and 2005, respectively [16]. And also Freudenberg [17] reported that vanillin was produced from lignin by the alkali-nitrobenzene method.

We here report the extraction of vanillin for the purpose of making the resource out of livestock excrement into useful plant polyphenol for a wide variety of industries.

\section{Materials and Methods}

The excrement of herbivorous animals, including cattle, goats, and horses (University of Miyazaki) and a carnivorous animal, tigers (Ueno Zoological Gardens, Tokyo, Japan), was used in our study. One-gram excrement and $4 \mathrm{~mL} \mathrm{H}_{2} \mathrm{O}$ were taken into the reactor, a stainless tube (SUS316) with the capacity of $5 \mathrm{~mL}$. Then the reactor was heated up to the temperatures (and pressures) of $100^{\circ} \mathrm{C}, 150^{\circ} \mathrm{C}(0.6 \mathrm{MPa})$, $200^{\circ} \mathrm{C}(1.5 \mathrm{MPa}), 250^{\circ} \mathrm{C}(3.9 \mathrm{MPa})$, and $300^{\circ} \mathrm{C}(8.3 \mathrm{MPa})$ each in the batch system. After treated for 60 minutes, the reactor was cooled down.

We analyzed the products in an aqueous solution with a high performance liquid chromatography. (HPLC) with a 600E System Controller, a 996 Photodiode Array Detector, and a 10190 HTR-B Temperature Control (Waters Co., MA, USA). A reversed-phase column (Shimadzu Shimpack CLC-ODS; $\phi=6.0 \mathrm{~mm}$; column length, $150 \mathrm{~mm}$; Kyoto, Japan) was used at the temperature of $50^{\circ} \mathrm{C}$. An aqueous solution of $2902.95 \mathrm{~mL} \mathrm{H} \mathrm{H}_{2} \mathrm{O}, 31.5 \mathrm{~mL}$ methanol, and $5.55 \mathrm{~mL}$ propan-2-ol, $60 \mathrm{~mL}$ acetic acid, $8.17 \mathrm{~g}$ sodium acetate was used as a mobile phase. The flow rate of the mobile phase was $0.7 \mathrm{~mL} / \mathrm{min}$ and the UV detector showed the absorbance at $280 \mathrm{~nm}$. We conducted the quantitative analyses of the plant polyphenol concentration using the HPLC of the samples with the area of each peak. We also used a liquid chromatography/mass spectrometer system (LC/MS) to reconfirm each peak obtained in HPLC analysis. The column (Tosoh TSK-GEL ODS- $80 ; \phi=4.6 \mathrm{~mm}$; column length $150 \mathrm{~mm}$; Tokyo, Japan) was applied for LC/MS. The temperature of column was $40^{\circ} \mathrm{C}$ and other conditions were the same as described in the study of HPLC except that ammonium acetate was used as a volatile salt instead of sodium acetate for the mobile phase.

\section{Results and Discussion}

Today there are two methods of production of vanilla. A conventional way is to extract it directly from the vanilla plant. The vanilla plants are native to Mexico, but people in Madagascar were the first to produce for commercial uses. The flavoring comes from the seedpod and the bean of the vanilla plants. The process of making vanilla into the spice is a very long and complicated method. Therefore, they could not yield a large quantity of vanilla. The other method is obtaining the vanilla from wood pulp lignin disposed in industry. Adschiri and colleagues not only extracted the lignin under supercritical water and succeeded in the production of the plant polyphenol but they also identified many other entities than that of vanillin. However, it takes much time and energy to refine the plant polyphenol.

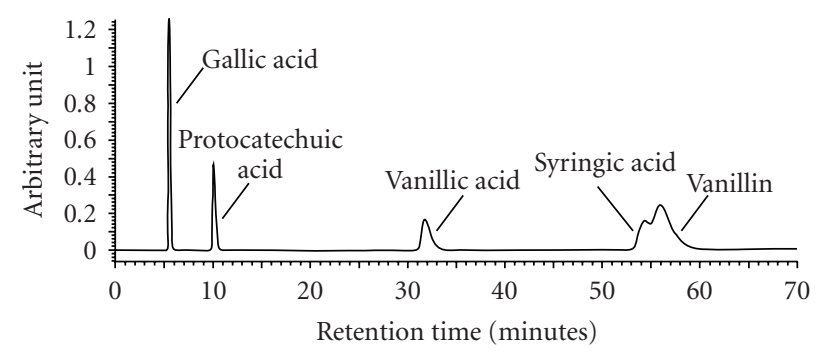

(a)

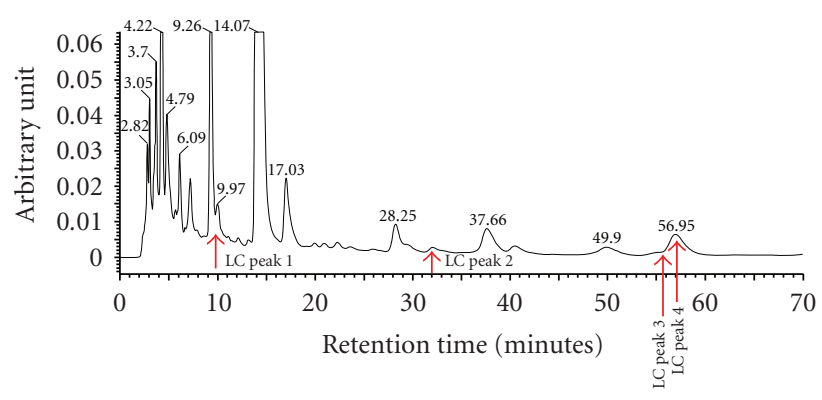

(b)

FIGURE 1: UV chromatograms of HPLC of (a) the standard reagents and (b) the cattle excrement treated at $200^{\circ} \mathrm{C}$. The chromatograms were obtained from the LC/MS system with the reversed-phase column (Tosoh TSK-GEL ODS-80; $\phi=4.6 \mathrm{~mm}$; column length $150 \mathrm{~mm}$ ). The temperature of column was $40^{\circ} \mathrm{C}$. The flow rate was $0.7 \mathrm{~mL} / \mathrm{min}$. The UV detector showed the absorbance at $280 \mathrm{~nm}$.

In order to turn the waste into useful products, we have devised a simple method for vanillin production with the lignin from the livestock excrements.

We have shown here in Figure 1(b) an HPLC profile of the products in the solution, which smells like coffee and cocoa powder, obtained from the cattle excrement at $200^{\circ} \mathrm{C}$ reaction. Following the HPLC profile of the standard compounds (Figure 1(a)), we can identify the following peaks: the peak of protocatechuic acid at 10 minutes, vanillic acid at 32 minutes, syringic acid at 55 minutes, and vanillin at 56 minutes. We can find the LC peaks 1 to 4 at the same retention time as those of standard compounds. For the confirmation of each substance we have conducted the liquid chromatography/mass spectrometer for the further study. Figure 2 shows the mass spectra obtained from the LC peaks 1 to 4 indicated in Figure 1(b).

We can identify the single major peak of ratio of mass to charge $(\mathrm{m} / \mathrm{z})$ with protocatechuic acid in Figure 2(a). It is also shown in Figures 2(c) and 2(d) with syringic acid and vanillin. On the other hand, we can identify two major peaks of $m / z$, which was shown in Figure 2(b); one is that of vanillic acid and the other remains unidentified.

We carried out the experiment with the different subcritical water reaction temperature for the purpose of the dependency of the products yields. Figure 3 shows the results of the quantitative analyses of each plant polyphenol. Our desired plant polyphenol is not found in the condition of $300^{\circ} \mathrm{C}$, which suggests that the temperature dependency on the product yields exists. Protocatechuic acid was obtained 


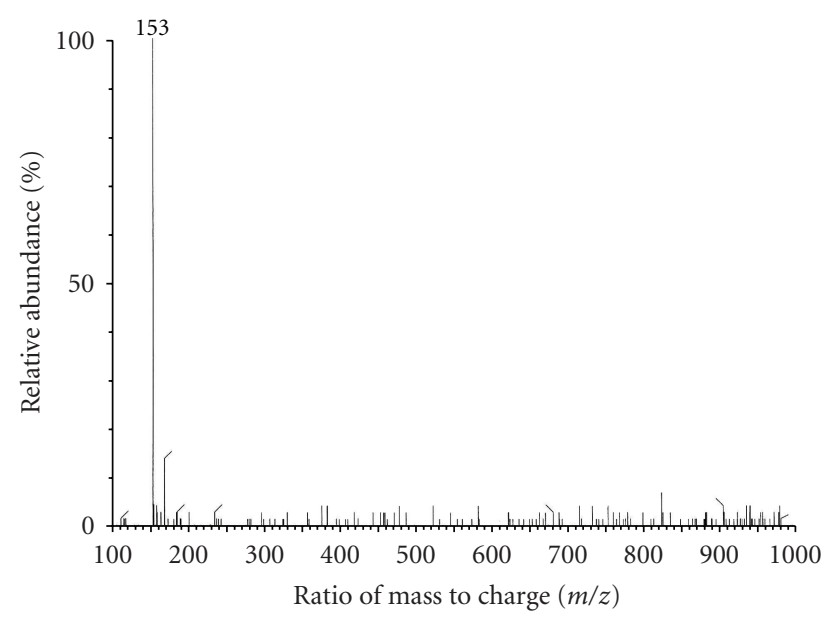

(a) LC peak 1

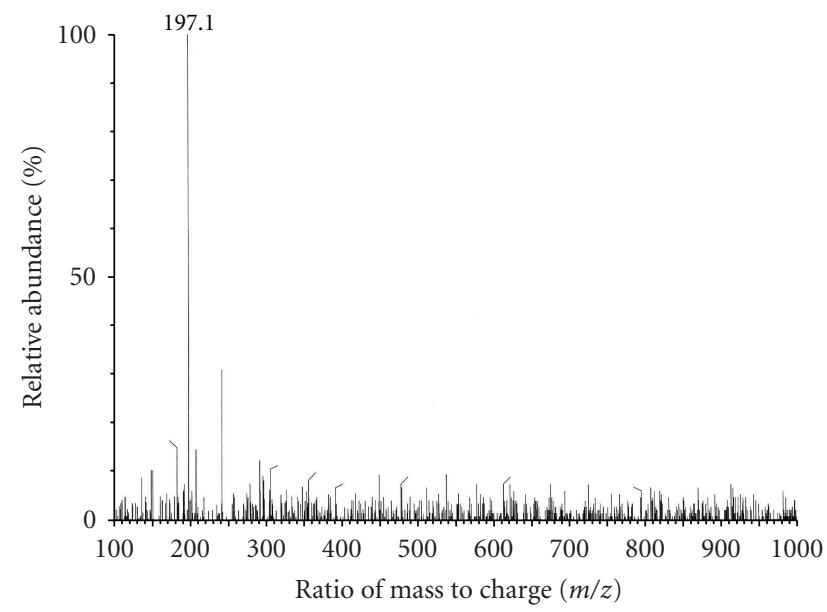

(c) LC peak 3

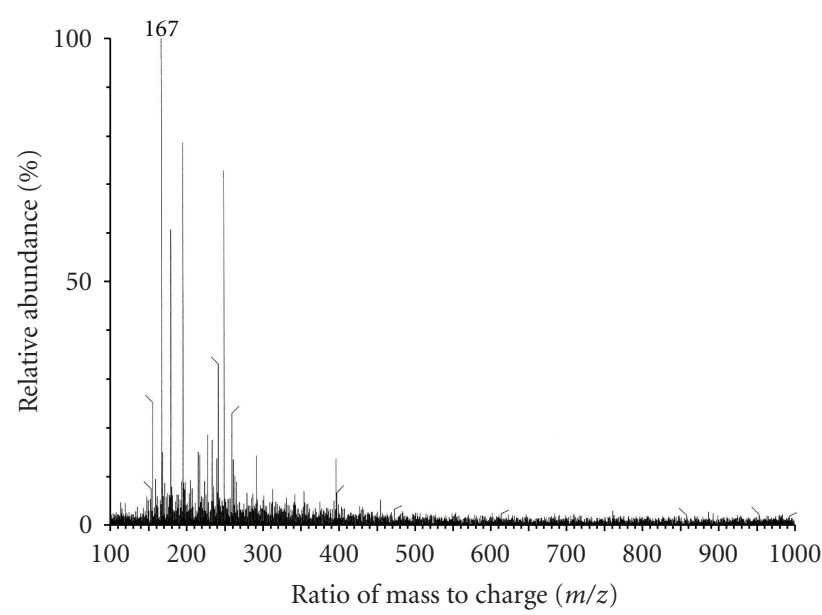

(b) LC peak 2

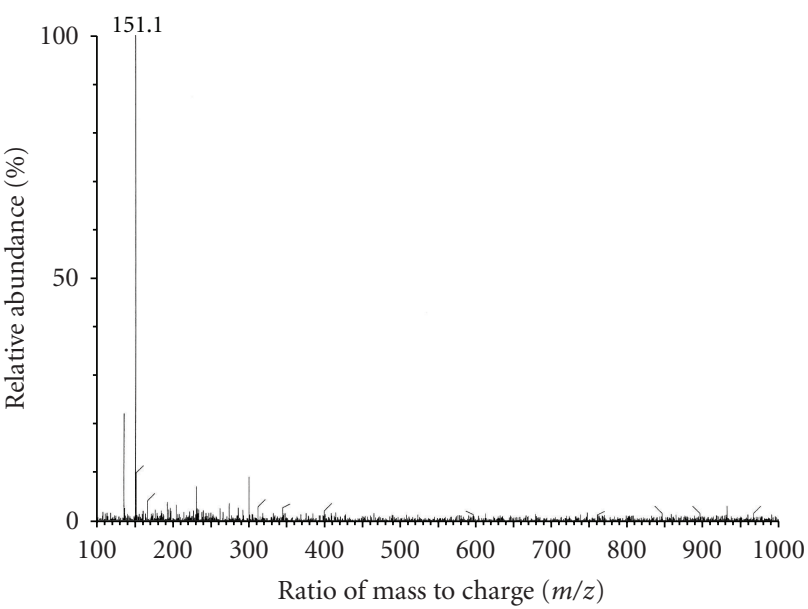

(d) LC peak 4

FIGURE 2: The mass spectra of the HPLC peaks of the cattle excrement treated at $200^{\circ} \mathrm{C}$. Mass scan was performed in negative ion detection mode after electrospray ionization. Theoretical ratios of mass to charge $(\mathrm{m} / \mathrm{z})$ of deprotonated ions $\left([\mathrm{M}-\mathrm{H}]^{-}\right)$of protocatechuic acid, vanillic acid, syringic acid and vanillin are 153.02, 167.03, 197.04, and 151.04, respectively.

at $200^{\circ} \mathrm{C}$. Vanillic acid was isolated from the excrement mostly at $150^{\circ} \mathrm{C}$ and its yield decreased at $200^{\circ} \mathrm{C}$. Syringic acid was obtained in the range of $150^{\circ} \mathrm{C}$ to $200^{\circ} \mathrm{C}$. Although we identified vanillin at $200^{\circ} \mathrm{C}$, at $250^{\circ} \mathrm{C}$ it yielded more but no vanillin was found when the reaction temperature was carried out $300^{\circ} \mathrm{C}$. The yield of vanillin at $250^{\circ} \mathrm{C}$ was the maximum. The total amount of vanillic acid and vanillin reached almost constant at $50 \mu \mathrm{g}$ by $1 \mathrm{~g}$ of excrement between temperatures in the range of $150^{\circ} \mathrm{C}$ to $250^{\circ} \mathrm{C}$. It is considered that vanillic acid was converted to vanillin via redox reaction under subcritical water. Further study is required to clarify this point.

We proceeded to further experiments with the other animals to identify production of vanillic acid and vanillin. We analyzed the products after the treatment with HPLC. Figure 4 shows the HPLC profiles of the products in the solution obtained from the cattle, goat, horse, and tiger excrement under the condition of $200^{\circ} \mathrm{C}$. We found peaks of vanillic acid and vanillin around 35 and 55 minutes, respectively, obtained from the products of the excrement cattle, goats, and horses: herbivorous animals. However, we could not find the products of the excrement of the tigers: carnivorous animal. Herbivorous animals take in the plants containing high content of lignin. The microbes in digestive organs digest the plant fiber. Most of the lignin contained in the plant fiber, however, cannot be digested by the microbes and other digestive enzyme. The lignin is difficult to digest for the herbivorous animals including the three animals we analyzed [18-24]. In the case of carnivorous animals, on the contrary, they take in mainly flesh meat that the digestive enzyme in their digestive organs hydrolyzed into the amino acid. We therefore reasoned that the excrement of the herbivorous animals is superior as a lignin source. Our experimental results are in agreement with the hypothesis as observed from the different amounts of the lignin in excrements between the herbivorous and carnivorous animals.

Although we have shown here that a valuable product could be extracted from excrements of the animals, they 


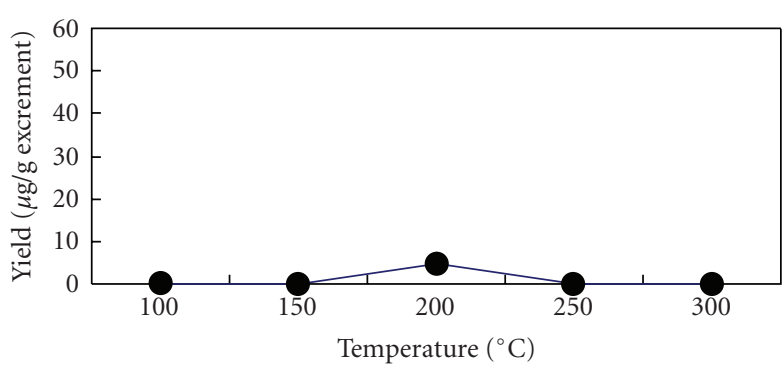

(a) Protocatechuic acid

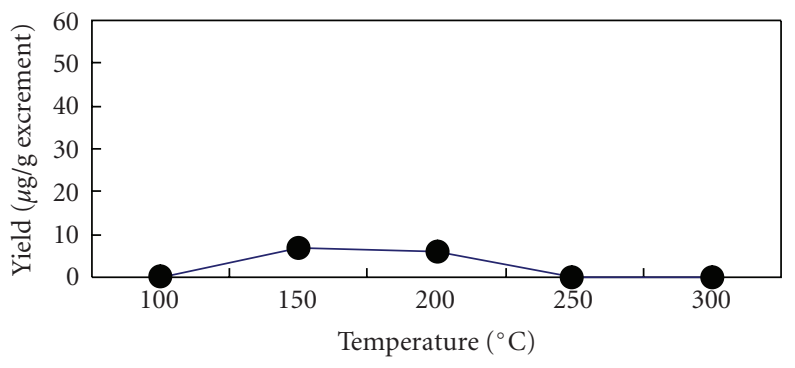

(c) Synringic acid

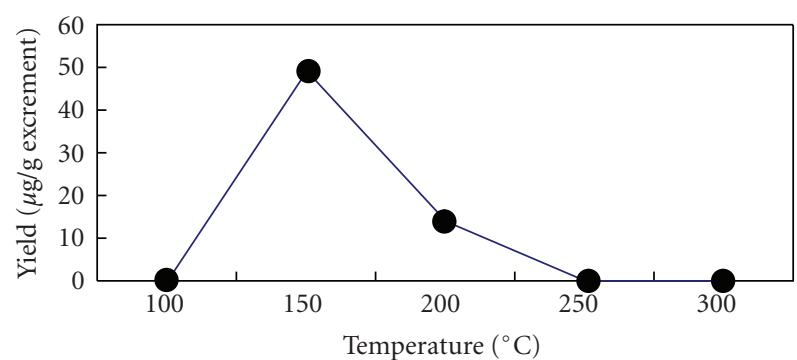

(b) Vanillic acid

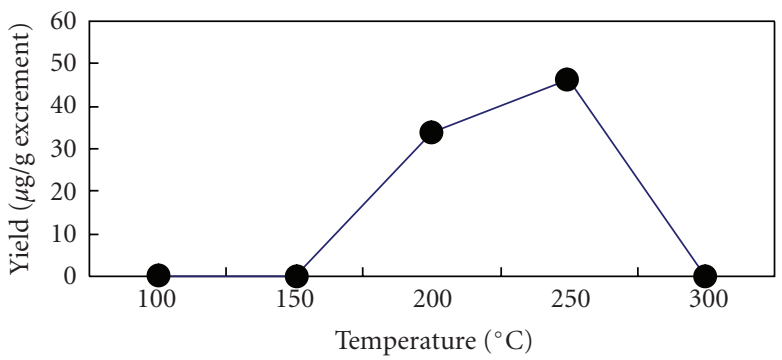

(d) Vanillin

FIGURE 3: Quantitative HPLC analysis of polyphenols extracted from the cattle excrement at 150, 200, 250 and $300^{\circ} \mathrm{C}$. (a) protocatechuic acid, (b) vanillic acid, (c) syringic acid, and (d) vanillin. The circles show the yield of plant polyphenol per $1 \mathrm{~g}$ of excrement. A reversed-phase column (Shimadzu Shim-Pack CLC-ODS; $\phi=6.0 \mathrm{~mm}$; column length, $150 \mathrm{~mm}$ ) was used at the temperature of $50^{\circ} \mathrm{C}$. An aqueous solution of $2902.95 \mathrm{~mL} \mathrm{H}_{2} \mathrm{O}, 31.5 \mathrm{~mL}$ methanol, and $5.55 \mathrm{~mL}$ propan-2-ol, $60 \mathrm{~mL}$ acetic acid, $8.17 \mathrm{~g}$ sodium acetate was used as a mobile phase. UV absorbance was detected at $280 \mathrm{~nm}$.

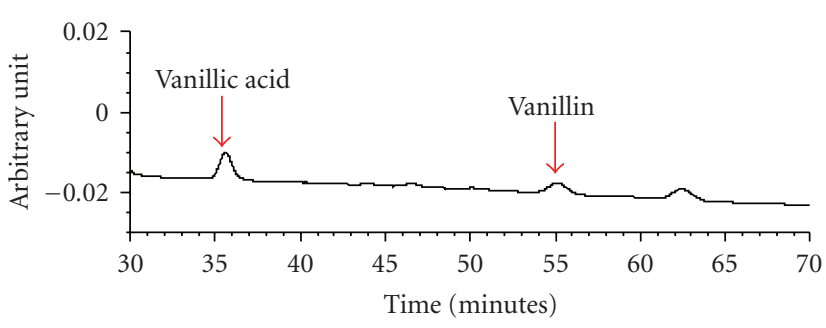

(a) Cattle

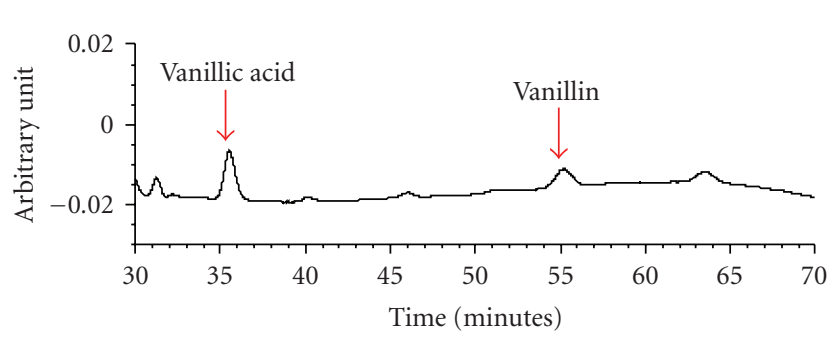

(c) Horse

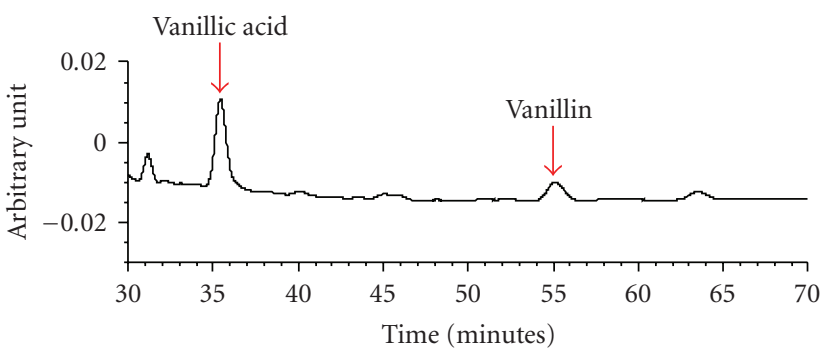

(b) Gout

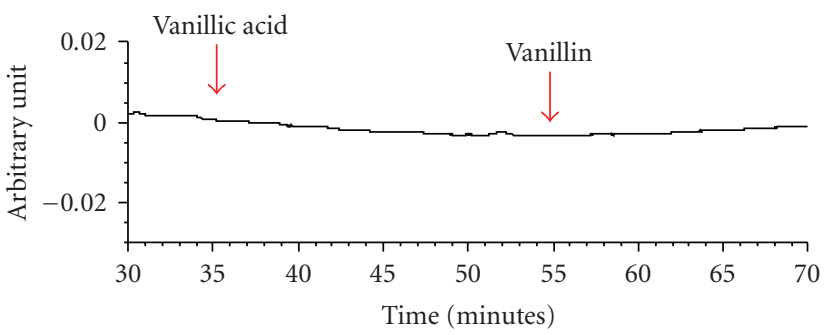

(d) Tiger

FIgURE 4: UV Chromatograms of (a) cattle, (b) goat, (c) horse, and (d) tiger excrement treated at $200^{\circ} \mathrm{C}$. We used HPLC system with the reversed-phase column (Shimadzu Shim-Pack CLC-ODS; $\phi=6.0 \mathrm{~mm}$; column length, $150 \mathrm{~mm}$ ) at the temperature of $50^{\circ} \mathrm{C}$. The mobile phase is the same as that of LC/MS; ammonium acetate was used instead of sodium acetate. The UV detector showed the absorbance at $280 \mathrm{~nm}$.

can be used as other resources. The biomasses are recyclable organic resources derived from plants and animals: livestock excrement, wood chip, and the chaff, for example. The livestock excrement has been attained up to 50 million tons per year in Japan. The problem of oil shortage in the near future is widely anticipated. We could avoid it by using the abundant excrement as a carbon resource. Furthermore, the suitability, as food, of the excrement products obtained in our method is now being tested on animals.

It is becoming increasingly apparent that the use of enormously large quantity of fossil fuel leads to the global 
warming. The more the consumption of it leads to the higher the concentration of $\mathrm{CO}_{2}$ in the atmosphere. The carbon given from the biomass, however, is originally fixed by the plant photosynthesis from the atmosphere. Our system does not release all the carbon atoms in the excrement into the atmosphere as $\mathrm{CO}_{2}$ but helps to keep the carbon atoms in the molecule of the plant polyphenol. Furthermore, agriculture not only provides us food, but also supports the biomass as natural resources. If we consider the shortage of the oil in the coming years, we need to find other ways to obtain materials extracted from oil at the present, rather than the conventional industrial method. Recycling is one way to overcome this problem. The usage of the biomass for industrial materials will be an alternative way for this purpose $[25,26]$. Our way of the production of polyphenol will provide alternative ways; actually, we have already succeeded in producing a kind of phenol-plastic from the polyphenol obtained from the livestock excrement by subcritical water reaction (data not shown).

Some compounds of the polyphenol are hard to synthesize, which leads us to develop a more effective and larger-scaled extraction system. The agriculture in this sense will also play a significantly important role in a sustainable society in the near future, implying the pathway, if we could develop the mass production system of polyphenol by using this method.

\section{Acknowledgments}

This work is partly supported by the Toray Research Center, Inc. The authors wish to thank Mr. S. Aizawa and Mr. S. Harada at AKICO Corporation for the experimental apparatus. They also thank Mr. K. Itou for the preparation of the manuscript.

\section{References}

[1] "The Law concerning the appropriate treatment and promotion of utilization of livestock manure," Japanese Law, no. 112, July 1999.

[2] J. Kimoto, Y. Harada, T. Ueda, and K. Katagiri, "Application of OG type Wet Catalytic Oxidation Process to many kind of industrial waste water," Aromatics, vol. 36, pp. 161-172, 1984.

[3] M. Oguchi and K. Nitta, "Evaluations of catalysts for wet oxidation waste management in CELSS," Advances in Space Research, vol. 12, no. 5, pp. 21-27, 1992.

[4] M. Oguchi and K. Nitta, "Organic waste processing using wet oxidation in CELSS," CELSS Journal, vol. 3, no. 1, 1991.

[5] J.-L. Faulon and P. G. Hatcher, "Is there any order in the structure of lignin?” Energy \& Fuels, vol. 8, no. 2, pp. 402-407, 1994.

[6] E. Dorrestijn, L. J. J. Laarhoven, I. W. C. E. Arends, and P. Mulder, "Occurrence and reactivity of phenoxyl linkages in lignin and low rank coal," Journal of Analytical and Applied Pyrolysis, vol. 54, no. 1-2, pp. 153-192, 2000.

[7] E. Alder, "Lignin chemistry-past, present and future," Wood Science and Technology, vol. 11, no. 3, pp. 169-218, 1977.

[8] C. W. Dence and S. Y. Lin, "Introduction," in Methods of Lignin Chemistry, S. Y. Lin and C. W. Dence, Eds., pp. 3-19, Springer, Berlin, Germany, 1992.

[9] C. Yokoyama, K. Nishi, A. Nakajima, and K. Seino, "Thermolysis of organosolv lignin in supercritical water and supercritical methanol," Sekiyu Gakkaishi, vol. 41, no. 4, pp. 243-250, 1998.

[10] C. W. Dence, "The determination of lignin," in Methods of Lignin Chemistry, S. Y. Lin and C. W. Dence, Eds., pp. 33-61, Springer, Berlin, Germany, 1992.

[11] K. Nakahara, "Recycling of plant polyphenol with supercritical water," in Fundamentals and Applications of Supercritical Fluids, Y. Arai, Ed., pp. 492-497, Techno-System, Tokyo, Japan, 2002.

[12] K. Okuda, M. Umetsu, S. Takami, and T. Adschiri, "Disassembly of lignin and chemical recovery-rapid depolymerization of lignin without char formation in water-phenol mixtures," Fuel Processing Technology, vol. 85, no. 8-10, pp. 803-813, 2004.

[13] K. Okuda, X. Man, M. Umetsu, S. Takami, and T. Adschiri, "Efficient conversion of lignin into single chemical species by solvothermal reaction in water-p-cresol solvent," Journal of Physics: Condensed Matter, vol. 16, no. 14, pp. S1325-S1330, 2004.

[14] M. Saisu, T. Sato, M. Watanabe, T. Adschiri, and K. Arai, "Conversion of lignin with supercritical water-phenol mixtures," Energy \& Fuels, vol. 17, no. 4, pp. 922-928, 2003.

[15] M. Osada, T. Sato, M. Watanabe, T. Adschiri, and K. Arai, "Low-temperature catalytic gasification of lignin and cellulose with a ruthenium catalyst in supercritical water," Energy \& Fuels, vol. 18, no. 2, pp. 327-333, 2004.

[16] Trade statistics of Japan, http://www.customs.go.jp/toukei/ info/index.htm.

[17] K. Freudenberg, "Über Lignin," Angewandte Chemie, vol. 52, no. 20, pp. 362-363, 1939.

[18] B. A. Dehority and R. R. Johnson, "Effect of particle size upon the in vitro cellulose digestibility of forages by rumen bacteria," Journal of Dairy Science, vol. 44, no. 12, pp. 2242-2249, 1961.

[19] C. H. P. Jones and K. A. Handreck, "The relation between the silica content of the diet and the excretion of silica by sheep," The Journal of Agricultural Science, vol. 65, pp. 129-134, 1965.

[20] L. D. Kamstra, A. L. Moxon, and O. G. Bentley, "The effect of stage of maturity and lignification on the digestion of cellulose in forage plants by rumen microorganisms in vitro," Journal of Animal Science, vol. 17, pp. 199-208, 1958.

[21] P. J. van Soest, "Symposium on nutrition and forage and pastures: new chemical procedures for evaluating forages," Journal of Animal Science, vol. 23, no. 3, pp. 838-845, 1964.

[22] D. C. Tomlin, R. R. Johnson, and B. A. Dehority, "Relationship of lignification to in vitro cellulose digestibility of grasses and legumes," Journal of Animal Science, vol. 24, no. 1, pp. 161-165, 1965.

[23] T. Kondo, S. Ara, K. Mizuno, and T. Kato, "Influence of lignin determination procedures on relationship between lignin content and digestibility in forages," Journal of Japanese Society of Grassland Science, vol. 33, no. 3, pp. 227-233, 1987.

[24] K. Toyokawa, K. Tsubomatsu, and T. Nomura, "Studies on the utilization of rice straw: IV the influence of cellulose, lignin and silica on the dry matter disappearance in the rumen of fistulated cow," Journal of Japanese Society of Grassland Science, vol. 21, no. 1, pp. 42-46, 1975.

[25] S. Sugiyama and K. Toyokawa, "Agricultural unused biomass as feed resources in recycle-based agricultural system," Grassland Science, vol. 51, no. 2, p. 213, 2005.

[26] M. Izumiya, S. Murayama, H. Mori, and Y. Sugimura, "Discharge and recycling channel of agricultural unused biomass in Aomori Prefecture," Grassland Science, vol. 51, no. 2, pp. 214-219, 2005. 

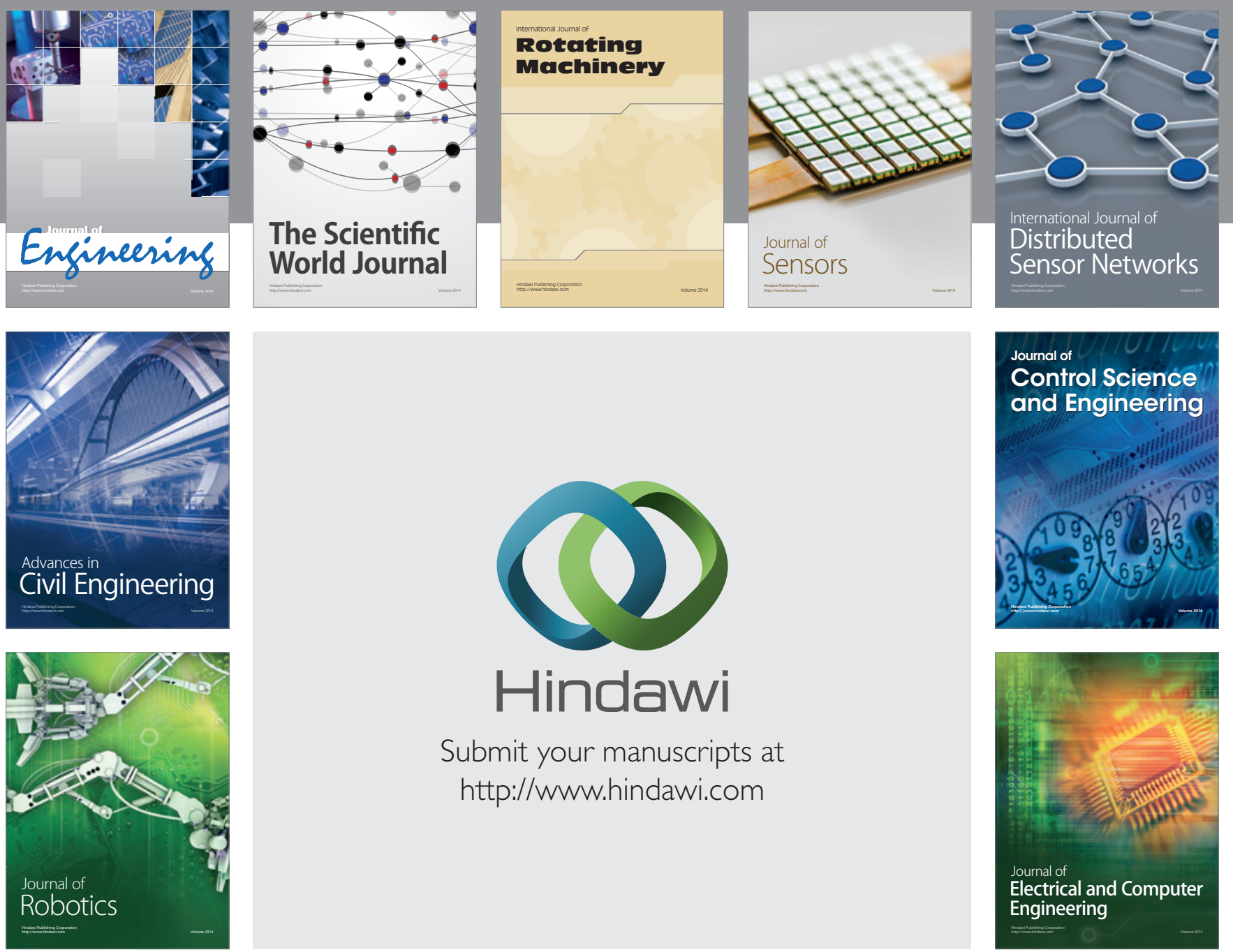

Submit your manuscripts at

http://www.hindawi.com
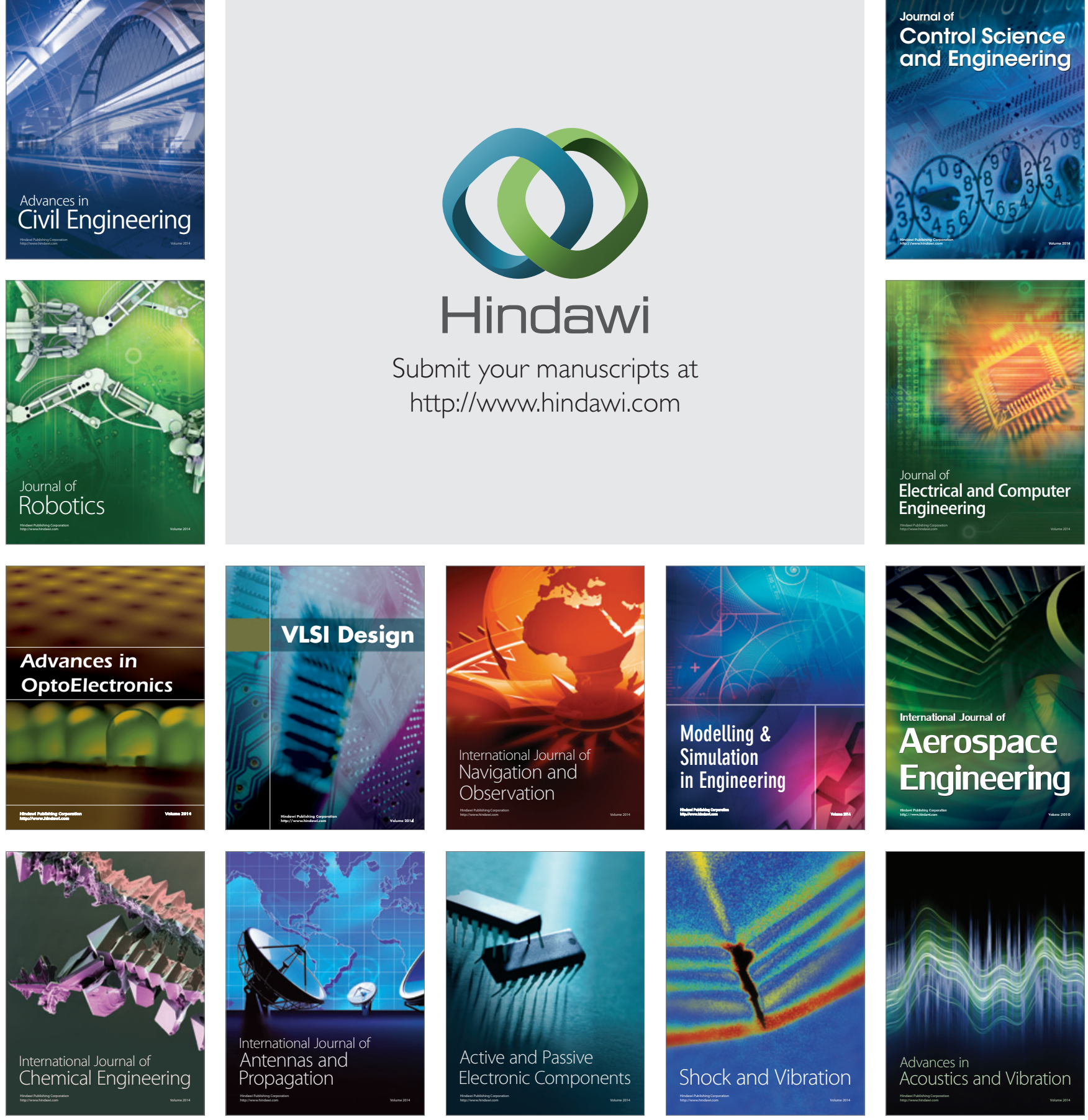